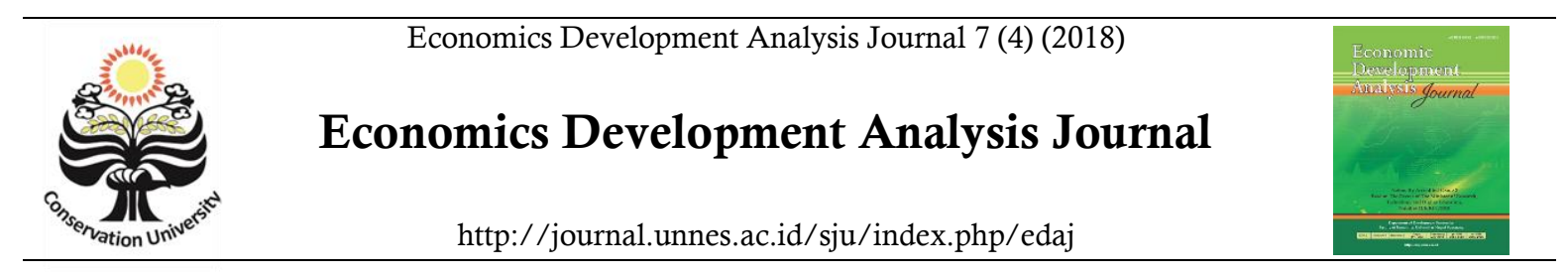

\title{
Valuasi Ekonomi dan Strategi Pengembangan Wisata Alam Pendakian dan Mawar Camp Area
}

Muhammad Izzuddin Furqony ${ }^{\bowtie}$

Jurusan Ekonomi Pembangunan, Fakultas Ekonomi, Universitas Negeri Semarang, Indonesia

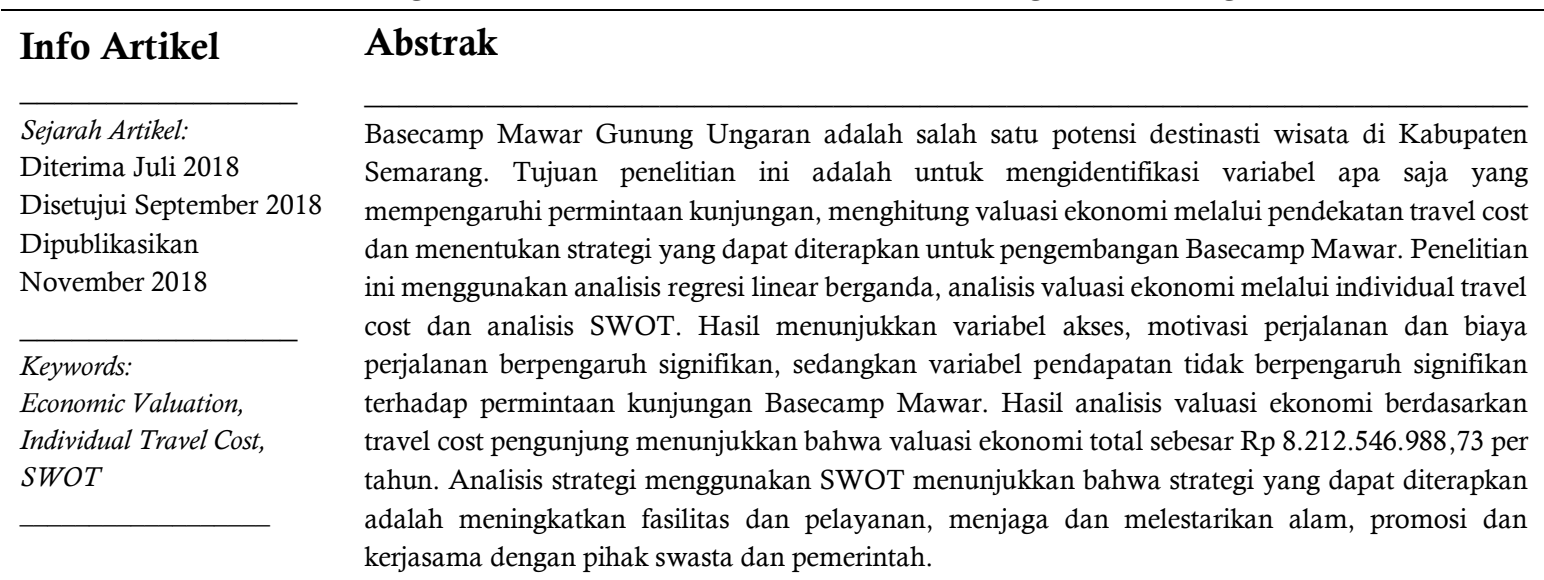

\begin{abstract}
Basecamp Mawar Gunung Ungaran is one of the potential tourist destinations in Semarang regency. The purpose of this study is to identify what variables affect the demand of visits, calculate the economic valuations through the travel cost approach and determine the strategies that can be applied to the development of Rose Basecamp. This study uses multiple linear regression analysis, economic valuation analysis through individual travel cost and SWOT analysis. The result shows that access variables, travel motivation and travel cost have significant effect, while income variable has no significant effect to the request of Basecamp Mawar visit. The result of economic valuation analysis based on travel cost of visitors shows that the total economic valuation is $R p 8,212,546,988,73$ per year. Strategy analysis using SWOT shows that the strategies that can be applied are improving facilities and services, preserving and preserving nature, promotion and cooperation with private and government parties.
\end{abstract}

(C) 2018 Universitas Negeri Semarang

${ }^{凶}$ Alamat korespondensi:
Gedung L2 Lantai 2 FE Unnes
Kampus Sekaran, Gunungpati, Semarang, 50229
E-mail: edaj@mail.unnes.ac.id
ISSN 2252-6965 


\section{PENDAHULUAN}

Jawa Tengah sebagai salah satu provinsi di Indonesia yang memiliki potensi besar untuk pariwisata. Banyaknya penawaran wisata yang diberikan tersebut menjadikan Jawa Tengah sebagai daerah tujuan wisata yang banyak dikunjungi oleh wisatawan baik wisatawan domestik maupun wisatawan mancanegara. Salah satu wisata alam yang banyak digemari saat ini baik dikalangan anak muda ataupun orang dewasa secara umum adalah wisata alam ke daerah pegunungan. Bentuk wisata ini berupa mengadakan camping atau perkemahan, mendaki pegunungan atau sekedar datang melihat pemandangan dari daerah ketinggian.

Salah satu tempat yang menjadi tujuan untuk wisata alam berupa pendakian gunung dan area kemping adalah Wisata Alam Pendakian dan Mawar Camp Area Gunung Ungaran atau biasa juga disebut Basecamp Mawar. Basecamp Mawar berlokasi di lereng Gunung Ungaran tepatnya di Desa Sidomukti, Kecamatan Bandungan, Kabupaten Semarang, Jawa Tengah.

Basecamp Mawar merupakan lokasi tujuan wisata alam yang berada di kawasan hutan Gunung Ungaran yang digunakan sebagai tempat untuk Pos Pendakian dan lokasi perkemahan. Kondisi Wisata Alam Pendakian dan Mawar Camp Area (Basecamp Mawar) Gunung Ungaran masih dalam tahap proses pengembangan. Basecamp Mawar selalu dikunjungi oleh pengunjung walaupun akses jalan menuju lokasi masih banyak yang rusak, fasilitas mushola, kamar mandi, dan warung yang kurang memadai. Keberadaan Basecamp Mawar memiliki potensi untuk dikembangkan dalam mendukung pengembangan ekonomi masyarakat sekitar.

Banyaknya pengunjung yang datang tentu dipengaruhi oleh faktor-faktor yang menyebabkan meningkatnya jumlah kunjungan ke Basecamp Mawar. Oleh karena itu perlu adanya penelitian mengenai faktor-faktor apa saja yang mempengaruhi banyaknya pengunjung yang datang ke Basecamp Mawar walaupun kondisi Basecamp Mawar masih dalam tahap pengembangan. Banyaknya pengunjung yang datang ke Basecamp Mawar tentu karena adanya ketersediaan membayar oleh pengunjung, ketersediaan membayar pengunjung bisa ditentukan dengan menganalisis nilai ekonomi melalui biaya perjalanan individu (individual travel cost) yang dikeluarkan pengunjung ke Basecamp Mawar.

Berdasarkan latar belakang tersebut penulis ingin mengangkat penelitian untuk mengidentifikasi faktor-faktor apa saja yang mempengaruhi jumlah kunjungan wisatawan Wisata Alam Pendakian dan Mawar Camp Area (Basecamp Mawar) Gunung Ungaran, berapa nilai ekonomi yang diperoleh pengunjung melalui pendekatan individual travel cost (biaya perjalanan) serta bagaimana menentukan strategi pengembangannya.

Penelitian ini bertujuan untuk menganalisis faktor-faktor apa saja yang mempengaruhi permintaan kunjungan Basecamp Mawar, menghitung valuasi ekonomi melalui pendekatan individual travel cost serta menentukan strategi pengembangan gungapengembangan Basecamp mawar kedepannya.

\section{METODE PENELITIAN}

Populasi dalam penelitian ini adalah pengunjung Basecamp Mawar yang melakukan rekreasi wisata alam dengan rata-rata sebanyak 3605 pengunjung pertahun. Sedangkan jumlah sampel didapat melalui rumus slovin dengan nilai e $10 \%$ sehingga diperoleh sampel sebanyak 97,30 pengunjung atau digenapkan menjadi 97 pengunjung. Metode sampling yang digunakan adalah quoted accidential sampling, yaitu pengambilan sampel dilakukan kepada siapa saja yang ditemui dilokasi namun dibatasi jumlahnya sesuai jumlah sampel yang dibutuhkan yaitu 97 responden.

Penelitian ini menggunakan metode analisis regresi linear dengan variabel jumlah permintaan kunjungan sebagai variabel dependen dan variabel akses, pendapatan, motivasi dan biaya perjalanan sebagai variabel independen. Kemudian dilakukan analisis untuk 
mengetahui pengaruh variabel akses, pendapatan, travel motivation dan biaya perjalanan terhadap jumlah permintaan kunjungan Basecamp Mawar dimana keseluruhan variabel dihitung dengan satuan skala likert yang diperolah dari data kuisioner. Sehingga diformulasikan sebagai berikut:

$\mathrm{Y}=\mathrm{f}(\mathrm{X} 1, \mathrm{X} 2, \mathrm{X} 3, \mathrm{X} 4)$

Keterangan:

Y : Jumlah permintaan kunjungan Basecamp Mawar

$\mathrm{X} 1 \quad$ : Akses

X2 : Travel motivation

X3 : Pendapatan

X4 : Biaya Perjalanan

Analisis lain yang digunakan adalah analisis valuasi ekonomi. Dalam penelitian ini untuk menghitung valuasi ekonomi digunakan metode biaya perjalanan individu, yaitu dengan menghitung surplus konsumen tiap individu per tahun. Untuk menghitung nilai surplus konsumen, digunakan formulasi sebagai berikut:

$$
\mathrm{VE}=\int_{P 0}^{P 1}(a-b P x) d P x
$$

Persamaan diatas digunakan untuk menghasilkan nilai ekonomi. Dimana VE adalah valuasi ekonomi per individu per tahun digunakan perhitungan integral terbatas, dengan batas atas yaitu harga tertinggi biaya perjalanan (P1) dan batas bawah adalah harga terendah biaya perjalanan (P0), sedangkan $(\mathrm{a}-\mathrm{bPx}) \mathrm{dPx}$ adalah fungsi permintaan dimana a adalah konstanta dan bPx adalah nilai koefisien biaya perjalanan. Metode selanjutnya yang digunakan adalah analisis SWOT (Strenght, Weakness, Opportunity, dan Treath) yang digunakan untuk menentukan strategi yang dapat dilakukan dalam pengembangan pariwisata berdasarkan kekuatan, kelemahan yang dimiliki objek wisata, serta peluang dan ancaman dari lingkungan eksternal.

\section{HASIL DAN PEMBAHASAN}

Untuk mengetahui pengaruh faktor-faktor apa saja yang mempengaruhipermintaan jumlah kunjungan dilakukan dengan penyebaran kuisioner kepada pengunjung sebagai responden. Berdasarkan hasil kuisioner kemudian diperoleh data tabulasi dengan variabel yang digunakan adalah variabel jumlah permintaan kunjungan sebagai variabel dependen dan variabel akses, pendapatan, motivasi dan biaya perjalanan sebagai variabel independen. Selanjutnya dilakukan olah signifikasi untuk mengetahui pengaruh variabel akses, pendapatan, motivasi perjalan dan biaya perjalan terhadap permintaan jumlah kunjungan Basecamp Mawar.

Hasil uji signifikasi yang telah dilakukan untuk mengetahui pengaruh variabel akses, pendapatan, motivasi perjalanan dan biaya perjalanan, diperoleh hasil regresi sebagai berikut:

Hasil penghitungan regresi tabel diatas diperoleh fungsi permintaan dengan formulasi sebagai berikut:

$\mathrm{Y}=-1.472918+0,282346 X_{1}-0,20023$
$X_{2}+0,680432 X_{3}+0,437841 X_{4}+\mathrm{e}$

Berdasarkan permintaan tersebut menunjukkan bahwa variabel Akses (X1) berpengaruh siginifikan terhadap permintaan jumlah kunjungan Basecamp Mawar, artinya ketika variabel akses meningkat sebesar satu persen maka akan mempengaruhi jumlah permintaan kunjungan Basecamp Mawar sebesar 0.282346 kunjungan dalam satu tahun terakhir.

Hasil variabel pendapatan (X2) sebesar 0.020023 menunjukkan bahawa apabila pendapatan naik sebesar satu rupiah maka permintaan kunjungan akan menurut sebesar 0.020023 dalam satu tahun terkhir. Ini menunjukkan bahwa ketika pengunjung memiliki pendapatan lebih mereka lebih memilih berkunjung ke tempat rekreasi taman bermain yang lebih mahal atau berkunjung ke tujuan wisata serupa yang lebih jauh dan lebih bagus dari Basecamp Mawar.

Variabel motivasi perjalanan (X3) bernilai sebesar 0.680432 menunjukkan bahwa ketika motivasi perjalanan meningkat sebesar satu persen maka jumlah permintaan kunjungan Basecamp Mawar akan meningkat sebesar 0.680432 kunjungan dalam satu tahun terakhir. 
Semakin besar motivasi dan tujuan pengunjung untuk datang maka semakin bertambah kunjungan yang dilakukan oleh pengunjung ke Basecamp Mawar atau datang kembali ke Basecamp Mawar.

Adapun variabel biaya perjalanan (X4) juga berpengaruh positif terhadap permintaan kunjungan Basecamp Mawar. Nilai sebesar 0.437841 menunjukkan bahwa apabila biaya perjalanan pengunjung meningkat sebesar satu persen maka permintaan kunjungan Basecamp
Mawar juga akan meningkat sebesar 0.437841 kunjungan dalam satu tahun terakhir. Hal ini membuktikan semakin besarnya biaya perjalanan membuktikan semakin besar biaya yang rela dikorbankan oleh pengunjung untuk datang berkunjung. Bisa dikatakan bahwa manfaat yang dirasakan oleh pengunjung yang datang berkunjung ke Basecamp Mawar besar sehingga pengunjung rela datang menghabiskan sejumlah uang mereka untuk berkunjung.

Tabel 2. Hasil analisis regresi linear berganda

\begin{tabular}{|c|c|c|c|c|}
\hline Variable & Coefficient & Std. Error & t-Statistic & Prob. \\
\hline $\mathrm{C}$ & -1.472918 & 0.459304 & -3.206850 & 0.0018 \\
\hline LOG(X1) & 0.282346 & 0.153694 & 1.837064 & 0.0694 \\
\hline LOG(X2) & 0.020023 & 0.083882 & 0.238703 & 0.8119 \\
\hline LOG(X3) & 0.680432 & 0.146314 & 4.650490 & 0.0000 \\
\hline LOG(X4) & 0.437841 & 0.133906 & 3.269772 & 0.0015 \\
\hline R-squared & 0.389588 & \multicolumn{2}{|c|}{ Mean dependent var } & 1.759804 \\
\hline Adjusted R-squared & 0.363049 & \multicolumn{2}{|c|}{ S.D. dependent var } & 0.305188 \\
\hline S.E. of regression & 0.243568 & \multicolumn{2}{|c|}{ Akaike info criterion } & 0.063332 \\
\hline Sum squared resid & 5.457950 & \multicolumn{2}{|c|}{ Schwarz criterion } & 0.196049 \\
\hline Log likelihood & 1.928391 & \multicolumn{2}{|c|}{ Hannan-Quinn criter. } & 0.116996 \\
\hline F-statistic & 14.67948 & \multicolumn{2}{|c|}{ Durbin-Watson stat } & 1.683158 \\
\hline Prob(F-statistic) & 0.000000 & & & \\
\hline
\end{tabular}

Sumber : Data primer, 2017 (diolah).

Hasil regresi antara jumlah permintaan kunjungan dengan biaya perjalanan menghasilkan fungsi permintaan seperti terlihat pada persamaan berikut ini.

$\mathrm{Y}=3,955081+3,07 \mathrm{E}-06 X_{4}$

$\mathrm{Dx}=\mathrm{Qx}=3,955081+0,00000307 \mathrm{P}$

Berdasarkan hasil persamaan tersebut digunakan untuk menghasilkan surplus konsumen sebagai nilai ekonomi. Untuk menghasilkan surplus konsumen per individu per tahun digunakan integral terbatas dari biaya perjalanan pengunjung. Batas atas adalah sebesar
Rp 834.000,- $\left(\mathrm{P}^{1}\right)$ dan batas bawah adalah sebesar $\mathrm{Rp} 12.000,-\left(\mathrm{P}^{0}\right)$. Untuk menghitung surplus konsumen digunakan persamaan berikut ini :

$$
\begin{aligned}
S K= & \int_{12.000}^{834.000} 3,955081+0,00000307 p d P \\
= & 2.278 .099,026 \text { per individu per tahun } \\
= & 759.366,342 \text { per per individu per satu } \\
& \text { kali kunjungan }
\end{aligned}
$$


Berdasarkan hasil perhitungan tersebut, kunjungan. Pengunjung yang datang ke maka diperoleh surplus konsumen per individu Basecamp Mawar rata-rata telah berkunjung pertahun adalah Rp 2.278.099,026. Pengunjung sebanyak 3 kali ke Basecamp Mawar. Sehingga yang datang ke Basecamp Mawar rata-rata telah diketahui bahwa kelebihan yang dinikmati berkunjung sebanyak tiga kali, sehingga pengunjung karena keninginan untuk membayar diketahui surplus yang dinikmati konsumen mereka melebihi kemampuan membayarnya sebesar Rp 759.366,342 per individu per satu kali $\quad$ yaitu sebesar Rp 138.964,--

Tabel 3. Nilai Bobot IFE dan EFE

\begin{tabular}{|c|c|c|c|c|}
\hline No & FAKTOR INTERNAL & RATING & ВОВОТ & SKOR \\
\hline & KEKUATAN & & & \\
\hline 1 & Keindahan Basecamp Mawar & 3,21 & 0,11 & 0,35 \\
\hline 2 & Kelestarian Sumber Daya Alam yang masih terjaga & 3,03 & 0,10 & 0,31 \\
\hline 3 & Kondisi lingkungan yang sejuk dan alami & 3,28 & 0,11 & 0,37 \\
\hline 4 & Lokasi Basecamp Mawar berdekatan dengan objek wisata lain & 2,99 & 0,10 & 0,30 \\
\hline \multirow[t]{3}{*}{5} & Dukungan pengelolaan dari masyarakat & 2,89 & 0,09 & 0,27 \\
\hline & JUMLAH & 15,40 & 0,52 & 1,60 \\
\hline & KELEMAHAN & & & \\
\hline 6 & Program pengembangan masih sederhana & 3,02 & 0,10 & 0,31 \\
\hline 7 & Sarana dan prasarana yang belum memadai & 2,86 & 0,09 & 0,27 \\
\hline 8 & Promosi yang belum maksimal & 2,84 & 0,09 & 0,27 \\
\hline 9 & Akses jalan menuju lokasi masih ada yang rusak & 3,04 & 0,10 & 0,31 \\
\hline \multirow[t]{3}{*}{10} & Keterbatasan anggaran untuk pengelolaan & 2,79 & 0,09 & 0,25 \\
\hline & JUMLAH & 14,54 & 0,48 & 1,40 \\
\hline & TOTAL IFE & 59,88 & 1,00 & 3,00 \\
\hline No & FAKTOR EKSTERNAL & RATING & ВОвОт & SKOR \\
\hline & PELUANG & & & \\
\hline 1 & $\begin{array}{l}\text { Terjadi peningkatan frekuensi kunjungan wisatawan dari tahun ke } \\
\text { tahun }\end{array}$ & 3,20 & 0,12 & 0,39 \\
\hline 2 & Konsep wisata ke alam sedang banyak digemari & 3,30 & 0,13 & 0,41 \\
\hline 3 & Membuka peluang kerja bagi masyarakat pemuda sekitar & 3,27 & 0,12 & 0,41 \\
\hline 4 & Sering diadakan event oleh pihak luar & 2,65 & 0,09 & 0,25 \\
\hline \multirow[t]{3}{*}{5} & Konsep pengembangan wisata alami (ekowisata) & 3,17 & 0,12 & 0,38 \\
\hline & JUMLAH & 15,59 & 0,58 & 1,84 \\
\hline & ANCAMAN/TANTANGAN & & & \\
\hline 6 & Persaingan dengan daerah lain dalam pengembangan wisata alam & 2,89 & 0,11 & 0,31 \\
\hline 7 & Dukungan pemerintah yang belum ada & 2,70 & 0,10 & 0,26 \\
\hline 8 & $\begin{array}{l}\text { Bencana alam, seperti kebakaran hutan sehingga mengganggu } \\
\text { ekosistem hutan }\end{array}$ & 2,71 & 0,10 & 0,26 \\
\hline \multirow[t]{3}{*}{9} & $\begin{array}{l}\text { Pencemaran lingkungan akibat rendahnya kepedulian pengunjung } \\
\text { terhadap lingkungan }\end{array}$ & 3,09 & 0,12 & 0,36 \\
\hline & JUMLAH & 11,40 & 0,42 & 1,19 \\
\hline & TOTAL EFE & 42,58 & 1,00 & 3,03 \\
\hline
\end{tabular}


Kekuatan adalah segenap potensi dan sumber daya yang dimiliki oleh Basecamp Mawar termasuk didalamnya keunggulan relatif terhadap pesaing dan yang konsumen yang ingin diberikan kepada pengunjung Basecamp Mawar. Indikator kekuatan sebagai berikut :Keindahan Basecamp Mawar, kelestarian Sumber Daya Alam yang masih terjaga, kondisi lingkungan yang masih sejuk dan alami, lokasi yang berdekatan dengan objek wisata lain, dukungan pengelolaan dari masyarakat

Berdasarkan hasil identifikasi internal, kelemahan yang dimiliki Basecamp Mawar adalah sebagai berikut: program pengembangan yang masih sederhana, arana dan prasarana yang belum memadai Promosi yang belum maksimal, akses jalan menuju lokasi masih banyak yang rusak, keterbatasan anggaran untuk pengelolaan, identifikasi faktor eksternal menghasilkan beberapa faktor peluang yang dimiliki oleh Basecamp Mawar.

Adapun peluang yang dimiliki Basecamp Mawar adalah sebagai berikut: terjadi pengingkatan frekuensi kunjungan wisatawan dari tahun ke tahun, konsep wisata ke alam sedang banyak digemari, membuka peluang kerja bagi masyarakat pemuda sekitar, sering diadakan event oleh pihak luar, konsep pengembangan wisata alami (ekowisata)

Adapun ancaman yang dimiliki oleh Basecamp Mawar adalah sebagai berikut, ukungan pemerintah yang belum ada, persaingan dengan daerah lain dalam pengembangan wisata alam, bencana alam, seperti kebakaran hutan yang dapat mengganggu ekosistem hutan, encemaran lingkungan akibat rendahnya kepedulian pengunjung terhadap lingkungan.

Berdasarkan data yang telah ditabulasi berdasarkan kuisioner yang telah didistribusikan terhadap responden, maka didapat dari rating dan bobot sebagai berikut.

Hasil penghitungan SWOT menunjukkan faktor kekuatan memiliki nilai yang lebih tinggi dari pada kelemahan dan memiliki nilai peluang yang lebih bagus dan lebih besar dibandingkan dengan ancaman. Nilai tersebut dapat dilihat sebagai berikut :

Faktor Internal Kekuatan - Kelemahan

$$
\text { : } 1,60-1,40=0,20
$$

Faktor Eksternal Peluang - Ancaman

$$
\text { : } 1,84-1,19=0,65
$$

Nilai-nilai hasil tersebut kemudian dimasukkan ke dalam Matriks Grand Strategy untuk melihat posisi Basecamp Mawar, sehinga kemudian bisa diketahui strategi yang tepat untuk pengembangan Basecamp Mawar seperti apa. Berdasarkan hasil nilai di atas maka posisi Basecamp Mawar pada Matriks Grand Strategy berada pada kuadran ke satu yang mendukung strategy agresif untuk pembangunan yang tepat, seperti pada gambar berikut:

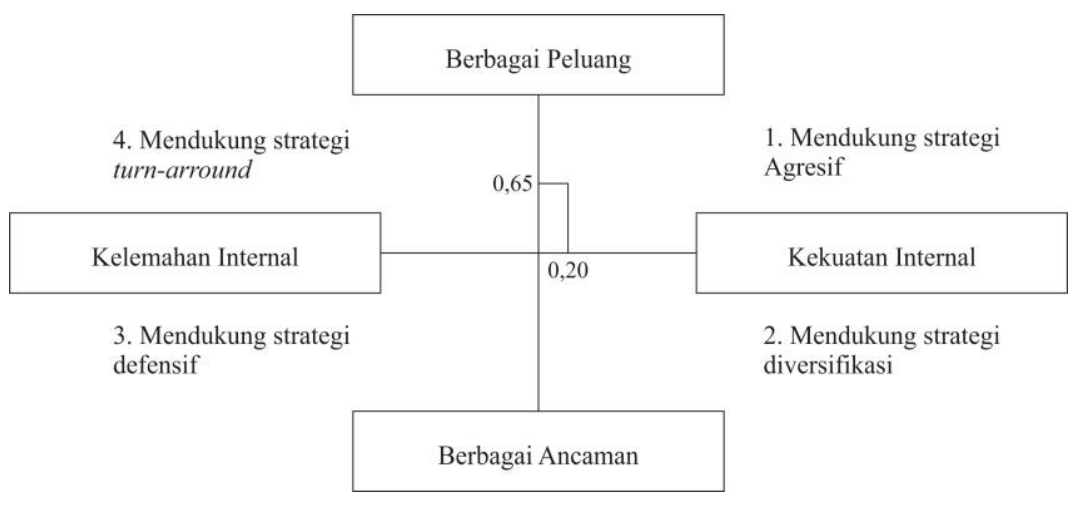

Gambar 2. Matriks Grand Strategy

Berdasarkan Gambar 2 posisi Basecamp menunjukkan bahwa Basecamp Mawar berada Mawar berada di kuadran 1, hal ini pada posisi yang sangat menguntungkan. Posisi 
ini menunjukkan bahwa Basecamp Mawar memiliki peluang dan kekuatan yang dominan dibandingkan dengan kelemahan serta ancaman yang ada. Strategi yang diterapkan dalam kondisi ini adalah mendukung strategi pertumbuhan agresif (growth oriented strategy). Berdasarkan tabel
IFE dan EFE serta matrik grand strategy yang telah dilakukan maka selanjutnya dilakukan penentuan strategi yang tepat untuk mendukung strategi pertumbuhan agresif Wisata Alam Pos Pendakian dan Mawar Camp Area (Basecamp Mawar) Gunung Ungaran.

Tabel 4. Strategi Pengembangan Basecamp Mawar

\begin{tabular}{|c|c|c|}
\hline & Kekuatan (S) & Kelemahan (W) \\
\hline Faktor Eksternal (EFAS) & $\begin{array}{l}\text { Keindahan Basecamp Mawar } \\
\text { Kelestarian Sumber Daya Alam } \\
\text { yang masih terjaga } \\
\text { Kondisi lingkungan yang sejuk } \\
\text { Lokasi Basecamp Mawar } \\
\text { berdekatan dengan objek wisata } \\
\text { lain } \\
\text { Dukungan pengelolaan dari } \\
\text { masyarakat }\end{array}$ & $\begin{array}{l}\text { Program pengembangan yang } \\
\text { masih sederhana } \\
\text { Sarana dan prasarana yang } \\
\text { belum memadai } \\
\text { Promosi yang belum maksimal } \\
\text { Akses jalan menuju lokasi } \\
\text { masih ada yang rusak } \\
\text { Keterbatasan anggaran untuk } \\
\text { pengelolaan }\end{array}$ \\
\hline Pelus & trate & $\mathrm{iWO}$ \\
\hline $\begin{array}{l}\text { Terjadinya pengingkatan } \\
\text { frekuensi kunjungan wisatawan } \\
\text { dari tahun ke tahun } \\
\text { Konsep wisata ke alam sedang } \\
\text { banyak digemari } \\
\text { Membuka peluang kerja bagi } \\
\text { masyarakat pemuda sekitar } \\
\text { Diadakannya event oleh pihak } \\
\text { luar Basecamp Mawar } \\
\text { Konsep pengembangan wisata } \\
\text { alami (ekowisata) }\end{array}$ & $\begin{array}{l}\text { Meningkatkan image positif } \\
\text { wisatawan terhadap Basecamp } \\
\text { Mawar sebagai wisata alam } \\
\text { Pengembangan dan peningkatan } \\
\text { kualitas produk wisata menjadi } \\
\text { lebih menarik } \\
\text { Menjaga dan mengontrol } \\
\text { kelestarian ekosistem alam dan } \\
\text { lingkungan Basecamp Mawar }\end{array}$ & $\begin{array}{l}\text { Optimalisasi website dan sosial } \\
\text { media Basecamp Mawar } \\
\text { Mengikuti berbagai event } \\
\text { promosi dan kerjasama wisata } \\
\text { Perbaikan akses dan } \\
\text { peningkatan sarana prasarana } \\
\text { Basecamp Mawar } \\
\text { Pelatihan dan peningkatan } \\
\text { kualitas pengelolaan dan SDM } \\
\text { secara berkala }\end{array}$ \\
\hline Ancaman (T) & ST & Strategi WT \\
\hline $\begin{array}{l}\text { Persaingan dengan daerah lain } \\
\text { dalam pengembangan wisata } \\
\text { alam } \\
\text { Dukungan pemerintah yang } \\
\text { belum ada } \\
\text { Bencana alam, seperti } \\
\text { kebakaran hutan sehingga } \\
\text { mengganggu ekosistem hutan } \\
\text { Pencemaran lingkungan akibat } \\
\text { rendahnya } \\
\text { pengunjung } \\
\text { lingkungan }\end{array}$ & $\begin{array}{l}\text { Peningkatan kerjasama dengan } \\
\text { berbagai pihak sektor usaha } \\
\text { dalam pengembangan Basecamp } \\
\text { Mawar } \\
\text { Peningkatan pengawasan } \\
\text { terhadap pengunjung yang } \\
\text { datang untuk berkemah } \\
\text { Penyediaan tempat-tempat } \\
\text { sampah di berbagai tempat } \\
\text { strategis untuk menghindari } \\
\text { pencemaran lingkungan oleh } \\
\text { pengunjung }\end{array}$ & $\begin{array}{l}\text { Menggandeng pemerintah } \\
\text { daerah untuk bekerjasama } \\
\text { dalam pengembangan, modal, } \\
\text { promosi serta pelatihan SDM } \\
\text { bagi pengelola Basecamp } \\
\text { Mawar } \\
\text { Pengadaan berbagai sarana } \\
\text { serta papan petunjuk mengenai } \\
\text { penjagaan lingkungan agar } \\
\text { terhindar dari perusakan } \\
\text { lingkungan oleh pengunjung } \\
\text { Penataan pengelolaan } \\
\text { Basecamp Mawar sesuai } \\
\text { dengan permasalahan yang } \\
\text { dimiliki. }\end{array}$ \\
\hline
\end{tabular}


Berdasarkan hasil analisis pada Tabel 4 menghasilkan empat sel kemungkinan strategi yang dapat diterapkan untuk pengembangan Basecamp Mawar berdasarkan potensi dan kondisi lingkungan seperti yang terlihat pada Tabel 4. Dimana strategi tersebut adalah sebagai berikut: Meningkatkan image positif wisatawan terhadap Basecamp Mawar sebagai wisata alam. Pengembangan dan peningkatan kualitas produk wisata yang ada sehingga menjadi lebih menarik., menjaga dan mengontrol kelestarian ekosistem alam dan lingkungan Basecamp mawar, optimalisasi website dan sosial media Basecamp mawar sebagai media promosi, mengikuti berbagai event promosi dan kerjasama wisata, perbaikan berbagai akses dan peningkatan sarana dan prasarana basecamp Mawar, pelatihan dan peningkatan kualitas pengelolaan SDM secara berkala, peningkatan kerjasama dengan berbagai pihak sektor usaha untuk pengembangan Basecamp Mawar, peningkatan pengawasan terhadap pengunjung yang datang berkemah atau melakukan pendakian gunung, penyediaan tempat sampah di berbagai posisi strategis untuk menghindari pencemaran lingkungan oleh pengunjung, menggandeng Dinas Pariwisata untuk bekerjasama dalam pengembangan, modal, promosi serta pelatihan SDM bagi pengelola, pemasangan berbagai papan petunjuk mengenai penjagaan lingkungan agar terhindar dari perusakan oleh pengunjung, penataan pengelolaan Basecamp Mawar sesuai permasalahan yang dimiliki.

\section{SIMPULAN}

Hasil uji regresi linier berganda mengenai jumlah permintaan kunjungan Basecamp Mawar dapat diketahui bahwa ada beberapa variabel dependen dalam penelitian yang signifikan pengaruhnya terhadap jumlah permintaan kunjungan Basecamp Mawar yaitu variabel independen akses, travel motivation dan biaya perjalanan berpengaruh signifikan positif terhadap variabel dependen permintaan jumlah kunjungan Basecamp Mawar. Sedangkan variabel independen pendapatan berpengaruh signifikan negatif terhadap jumlah permintaan kunjungan Basecamp Mawar.

Berdasarkan hasil analisis valuasi ekonomi diperoleh surplus konsumen wisatawan adalah sebesar Rp 2.278.099,026 per individu per tahun atau sebesar Rp 759.366,342 per satu kali kunjungan. Hal ini mengindikasikan bahwa besarnya manfaat yang diperoleh oleh wisatawan melebihi rata-rata biaya perjalanan yang harus dikeluarkan wisatawan yaitu sebesar Rp 138.964 per kunjungan. Berdasarkan hasil perhitungan untuk nilai total ekonomi Basecamp Mawar melalui pendekatan biaya perjalanan individu maka diperoleh nilai total ekonomi Basecamp Mawar adalah sebesar Rp 8.212.546.988,73 per tahun.

Berdasarkan hasil analisis SWOT yang telah dilakukan, dapat disimpulkan bahwa strategi pengembangan yang dapat dilakukan untuk pengembangan Basecamp Mawar melalui strategi pertumbuhan agresif adalah dengan meningkatkan dan menata seluruh fasilitas dan pelayanan pengunjung demi menjaga image positif Basecamp Mawar sebagai wisata alam, menjaga dan melindungi kelestarian alam Basecamp Mawar, optimalisasi promosi dan kerjasama dengan berbagai pihak untuk perkembangan Basecamp mawar.

\section{DAFTAR PUSTAKA}

Arikunto, Suharsimi. 2010. Prosedur Penelitian Suatu Pendekatan Paraktik. Jakarta. Rineka Cipta.

Badan Pusat Statistik Kabupaten Semarang. 2016: Kabupaten Semarang dalam angka 2016

Hermansyah dan Busori Sunaryo. 2016. Pengembangan Marine Ecotourism Bontang Kuala Melalui Community Development PT Badak NGL. Jurnal. Economics Development Analysis Journal, Vol 5 No.1/2016

Baskoro, Dwi Hary. 2013. Analisis Kunjungan Objek Wisata Lawang Sewu di Kota Semarang. Skripsi. Fakultas Ekonomika dan Bisnis. Universitas Diponegoro.

Fathurrahmi, Fitri. 2016. Analisis Faktor-Faktor yang Mempengaruhi Permintaan Wisatawan Terhadapa Objek Wisata Pantai Gandoriah Kota Pariaman. Skripsi. Fakultas Ekonomi. Universitas Andalas. 
Muhammad Izzuddin Furqony / Economics Development Analysis Journal 7 (4) (2018)

Indah, Irma Afia Salma dan Susilowati. 2004. Analisis Permintaan Objek Wisata Alam Curug Sewu. Kabupaten Kendal dengan Pendekatan Travel Cost. Jurnal. Jurnal Dinamika Pembangunan, Vol 1 No. 2/Des 2004.

Rangkuti, Freddy. 2015. Teknik Membedah Kasus Bisnis Analisis SWOT. Jakarta: PT Gramedia Pustaka Utama.

Yoeti. Oka A. 1982. Pengantar Ilmu Pariwisata. Bandung: Angkasa. 